\title{
Охріменко О.В
}

\section{МЕТОДИ ПІДВИЩЕННЯ ТОЧНОСТІ ПОЗИЦІОНУВАННЯ ОБ'СКТІВ ЗАСОБАМИ СУПУТНИКОВОЇ НАВІГАЦЇ̈}

Розглянуто аналіз засобів обробки навігаційних даних у системах відстеження рухомих об'єктів, а саме розглянуто метод який підвищує точність вимірювання координат, ие алгоритм фільтрачії Каймана .Значною мірою че стосується різних рухомих об'єктів організачіï руху повітряного ,морського, річкового, автомобільного ци залізничного транспорту, а також використання сучасних супутникових навігачійних систем $у$ суміжних областях, таких як геодезія й картографія, землевпорядження, моніторинг земної поверхні. Розглянуто Алгоритм фільтрації Калмана - послідовний рекурсивний алгоритм, який використовує прийняту модель динамічної системи для отримання оцінки, щзо може бути істотно скоригована в результаті аналізу кожної нової вибірки вимірювань у часовій послідовності. Це рекурентний метод, який можна віднести за своїм алгоритмом до метода заміщення. Алгоритм фільтращії Калмана застосовується в прочесі управління багатьма складними динамічними системами, так як ие математичний апарат, який дозволяє згладжувати дані на льоту, не накопичуючи їх для аналізу. При управлінні динамічною системою, пери за все, необхідно повністю знати ї̈ фазовий стан в кожен момент часу, але виміряти всі змінні, якими необхідно управляти, не завжди можливо, $i$ в ичих випадках фільтр Калмана є тим засобом, який дозволяє відновити відсутню інформацію за допомогою наявних неточних (зашумленних) вимірювань.

Ключові слова: супутникові навігаџійні системи, методи обробки навігаційних даних, точність вимірювання координат, метод Калмана.

Постановка проблеми. За останні півтора десятка років став доступним для використання значний потенціал Глобальної системи визначення місцеположення (GPS), призначеної для навігації та визначення координат різних об'єктів, для наукових та прикладних досліджень. Головними факторами бурхливого розвитку GPS є iї всепогодність, оперативність, висока вартість. До цього слід додати, що конфігурація орбіт GPS-супутників дозволяє практично 3 будь-якої точки земної поверхні приймати сигнали щонайменше від чотирьох супутників, а як показує практика спостережень їх число коливається від п’яти до десяти. Існує ряд факторів, які впливають на точність вимірювання та достовірність отриманої інформації. Мета роботи- дослідити метод Калмана обробки навігаційних даних з метою підвищення точності визначення місцезнаходження рухомого об'єкта та достовірності отриманої інформації .

Аналіз останніх досліджень. На сьогоднішній день у відкритих джерелах інформації відомостей про алгоритми й методику комплексної попередньої оцінки точністних характеристик GNSS, стосовно до рухомих об'єктів, не виявлено. Проте, слід зазначити, що рядом компаній офіційно поширюються програмні продукти прогнозування точністних характеристик GNSS. Наприклад, Побудова GPS-мереж вимагає врахування специфіки GPSтехнологій. До них слід віднести: залежність точності визначення компонент векторів від їх довжини та тривалості GPS-вимірювань [1,2]. Посібники практичного застосування GPSтехнологій, мають суттєві розбіжності щодо рекомендацій із тривалості спостережень на векторах із довжинами у межах 10-50 км. Крім цього ці рекомендації не завжди чітко визначені і достовірні. У технічних паспортах GPS приймачів для векторів довжиною до 1020 км, зазвичай, наводяться регресійні залежності точності виміру векторів від їхньої 
довжини. Однак вони не враховують тривалості спостережень, та факторів які можуть впливати на похибку позиціонування, не завжди спираються на методи ,які запропоновані. Тому в цій роботі, було поставлено мету ,розглянути метод Калмана, які на думку автора дають найбільш точний результат вимірювання.

Мета дослідження. Основною метою дослідження є методи обробки навігаційних даних у системах у системах відстеження рухомих об’єктів, а саме розглянуто метод який підвищує точність вимірювання координат, це алгоритм фільтрації Калмана.

Основний матеріал дослідження. Фактори, які впливають на похибку позиціонування координат і методи, які підвищують точність вимірювання координат.

Проаналізуемо фактори,які впливають на похибку позиціонування.Основними джерелами помилок, що вносять похибки в обчислення точності навігаційних повідомлень у системі GPS.

тропосферні затримки сигналу - величина похибки безпосередньо залежить від метеорологічних параметрів (тиск, вологість, температура,), а також від висоти супутника над горизонтом. Компенсація тропосферних затримок проводиться шляхом розрахунку математичної моделі цього шару атмосфери. Значення похибок не перевищують 30 м [3,4];

похибка визначення відстані до супутника - помилка не корельована з іншими видами похибок. Її величина не перевищує 10 м;

ефемеридна похибка - помилки обумовлені розбіжністю між фактичним положенням супутника і його розрахунковим положенням. Значення похибки зазвичай не більше 3 м. $[5,6]$

помилки обчислення орбіт - з'являються внаслідок неточностей прогнозу і розрахунку ефемерид супутників, виконуваних в апаратурі приймача. Похибка призводить до помилки вимірювання координат близько 1-2 м [7, 8];

похибка неточного визначення часу - призводить до виникнення систематичної помилки визначення координат близько 0.6 м. Усувається за допомогою встановлення сервера точного часу на приймачі;

інструментальна помилка приймача - зумовлена наявністю шумів в електронному тракті приймача. Відношення сигнал/шум приймача визначає точність процедури порівняння, прийнятого від супутника і опорного сигналу, тобто похибка обчислення псевдодальності. Призводить до виникнення координатної помилки порядку 1.2 м $[9,10]$;

багатопроменевий прийом - з'являється в результаті вторинних відображень сигналу супутника від великих перешкод, розташованих в безпосередній близькості від приймача. Виникає явище інтерференції і вимірювана відстань виявляється більше дійсної. Найкращим способом боротьби вважається раціональне розміщення антени приймача щодо перешкод;

геометричне розташування супутників - при обчисленні сумарної помилки необхідно врахувати взаємне положення приймача і супутників. Для цього вводиться спеціальний коефіцієнт геометричного зниження точності GDOP (Geometric Dilution Of Precision), на який необхідно помножити всі перераховані вище помилки, щоб отримати результуючу помилку. Вона обернено пропорційна обсягу фігури, яка буде утворена, якщо провести поодинокі вектори від приймача до супутників. Велике значення GDOP свідчить про невдале розташування сателіта і велике значення помилки [10].

Розглянемо методи, які підвищують точність вимірювання.

1. Метод зіставлення (Messmethode mit direktem Vergleich)- метод прямого вимірювання 3 одноразовим порівнянням вимірюваної величини 3 усіма вихідними величинами багатозначної нерегульованої міри. Приклади 1. Вимірювання довжини лінійкою з поділками. 2. Вимірювання інтервалу часу годинником.

2. Метод одного збігу - метод прямого вимірювання 3 одноразовим порівнянням вихідних величин двох багатозначних нерегульованих мір, 3 різними за значеннями ступенями, нульові позначки яких зсунуті між собою на вимірювану величину.

Приклади: вимірювання довжини за допомогою двох лінійок з поділками, ціни яких знаходяться в певному відношенні (штангенциркуль); вимірювання часу за допомогою двох 
послідовностей періодичних імпульсів, періоди яких знаходяться в певному відомому відношенні.

Метод збігу полягає в тому, що різниця міх ефектами, які викликані діяннями вимірюваної і зразкової величини, визначається за збігом шкал або періодичних сигналів. (Приклади: вимірювання довжини штангенциркулем з ноніусом та частоти стробоскопом).

3. Метод подвійного збігу(метод коінциденції, Koinzidenzmessmethode) - метод прямого вимірювання з одноразовим порівнянням двох квантованих фізичних величин: вимірюваної та відтворюваної багатозначною нерегульованою мірою.

Приклади: вимірювання зі стикованих інтервалів часу за допомогою послідовності періодичних імпульсів з відомим значенням їх періоду; вимірювання зі стикованих відрізків довжини за допомогою лінійки з відомим значенням поділок.

4. Метод зрівноваження 3 регульованою мірою(Nullmessmethode) - метод прямого вимірювання 3 багаторазовим порівнянням вимірюваної величини та величини, що відтворюється мірою, яка регулюється, до їх повного зрівноваження. Приклад Вимірювання електричної напруги компенсатором; зважування на рівноплечих терезах (метод протиставлення).

Цей метод ще має назву - нульовий метод вимірювання, бо відрізняється тим, що результуючий ефект діяння вимірюваної X і зразкової Х3 величин на пристрій порівняння доводять до нуля.

5. Диференційний метод (різницевий метод, Differentielle Messung) - метод вимірювання, за яким невелика різниця між вимірюваною величиною та вихідною величиною одноканальної міри вимірюється відповідним засобом вимірювання. Диференціальний метод вимірювань - метод вимірювань, за якого вимірювана величина порівнюється з однорідною величиною, що має відоме значення, незначно відрізняється від вимірюваної величини, при якому вимірюється різниця між цими двома значеннями.

6. Meтод заміщення(Substitutions-Messmethode) - метод непрямого вимірювання 3 багаторазовим порівнянням до повного зрівноваження вихідних величин вимірювального перетворювача 3 почерговим перетворенням ним вимірюваної величини та вихідної величини регульованої міри.

7. Метод заміщення - метод вимірювань, при якому ефект діяння вимірюваної величини на пристрій порівняння (компаратор, вимірювальний прилад) запам'ятовується, а потім відновлюється діянням на нього зразкової величини. Приклад - вимірювання опору неточною мостовою схемою з застосуванням заміщуючого магазина опору. 3 визначень диференціального і нульового методів вимірювань випливає, що вони є окремими випадками інших методів порівняння 3 мірою, причому кожний з них визначається ступенем повноти реалізації цих методів. Нульовий метод має місце при повній компенсації, повному протиставленні, заміщенні чи збігу (в межах можливостей компаратора), а диференціальний - при неповній реалізації цих методів.

8. Компенсаційний метод вимірювань полягав в тому, що на вході пристрою порівняння (компаратора) одночасно діють дві величини - полярна або векторна вимірювана і такої ж фізичної природи зразкова величина, розмір якої відтворюється мірою, а співвідношення між їх розмірами визначається за вихідним сигналом пристрою порівняння. Приклад вимірювання напруги постійного струну за допомогою компенсатора шляхом її порівняння 3 ЕРС нормального елемента $[4,5]$. На прикладі розглянемо метод, який підвищує точність вимірювання.

\section{Метод , який підвищус точність вимірювань (метод Калмана)}

Алгоритм фільтрації Калмана - послідовний рекурсивний алгоритм, який використовує прийняту модель динамічної системи для отримання оцінки, що може бути істотно скоригована в результаті аналізу кожної нової вибірки вимірювань у часовій послідовності $[1,2]$. Це рекурентний метод,який можна віднести за своїм алгоритмом до метода заміщення. Цей алгоритм застосовується в процесі управління багатьма складними динамічними системами, так як це математичний апарат, який дозволяє згладжувати дані на льоту, не 
накопичуючи їх для аналізу. При управлінні динамічною системою, перш за все, необхідно повністю знати іiі фазовий стан в кожен момент часу. Але виміряти всі змінні, якими необхідно управляти, не завжди можливо, і в цих випадках фільтр Калмана є тим засобом, який дозволяє відновити відсутню інформацію за допомогою наявних неточних (зашумленних) вимірювань [3].

Також даний метод фільтрації використовується для обробки даних від датчиків і будьяких пристроїв. Як правило, такі показники схильні до шумів і відхилень, їх потрібно відсікати. Алгоритм фільтрації Калмана дозволяє відкидати піки(викиди) [2] і бачити усереднену, найімовірнішу картину процесу.

По-перше, фільтр Калмана є алгоритмом оптимальної рекурсивної обробки даних. Існує безліч способів визначення оптимальних засобів, що залежать від критеріїв, обраних для оцінки ефективності. Одним з аспектів оптимальності є те, що фільтр Калмана включає всю інформацію, яка може бути надана йому. Він обробляє всі дані доступні для виміру, незалежно від їх точності, для оцінки поточного значення змінних, що представляють інтерес, з використанням:

знання динаміки системи і вимірювального пристрою;

статистичний опис системних шумів, помилок вимірювань і невизначеності в моделях динаміки і будь-яку доступну інформацію про вихідних умовах цікавлять змінних $[7,8]$

На (рис. 1) зображена типова ситуація, при якій фільтр Калмана може бути використаний безпосередньо. Деяка система управляється деякими відомими елементами управління, а вимірювальні пристрої забезпечують цінність певних відповідних величин. Знання цих системних входів і виходів - це все, що явно $є$ з фізичної системи для цілей оцінки.

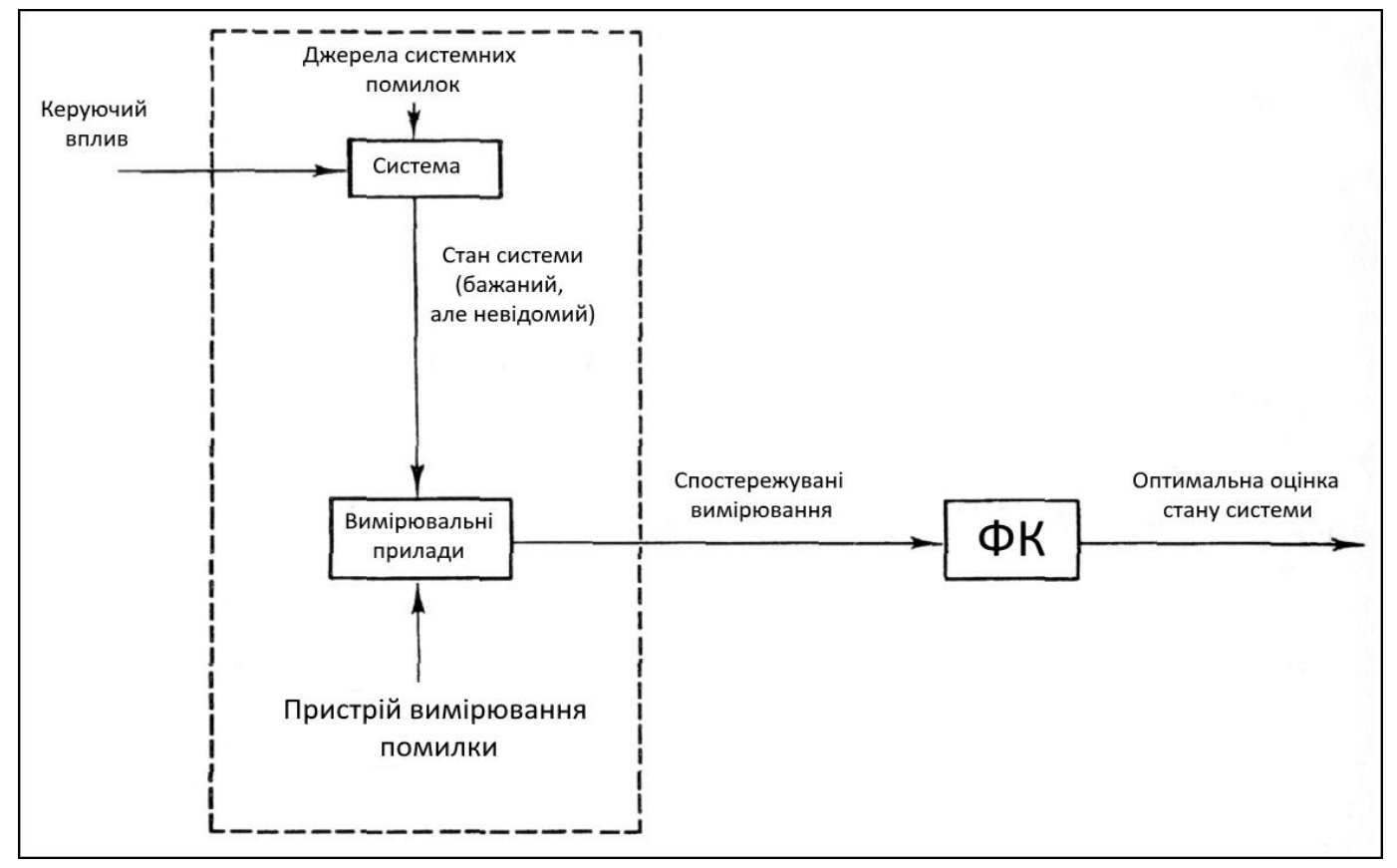

Рис. 1. Типове застосування фільтра Калмана

Також даний метод фільтрації використовується для обробки даних від датчиків і будьяких пристроїв. Як правило, такі показники схильні до шумів і відхилень, їх потрібно відсікати. Алгоритм фільтрації Калмана дозволяє відкидати піки(викиди) [2] і бачити усереднену, найімовірнішу картину процесу. 


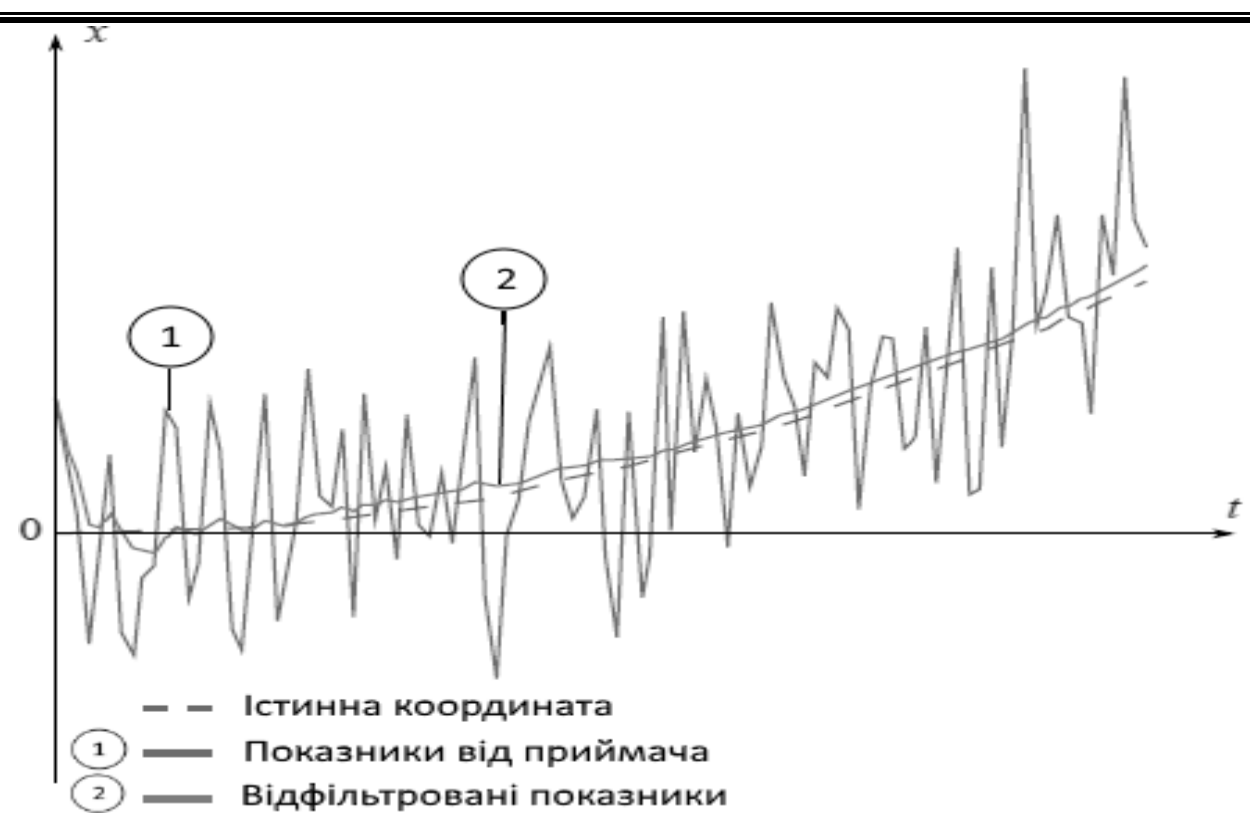

Рис.2. Дані, отримані з імітаційного GPS приймача

На (рис. 2) зображено дані, отримані з імітаційного GPS приймача. Використання фільтра Калмана дає можливість задати апріорнуінформацію про характер системи, зв'язку змінних і на підставі цього будувати більш точну оцінку, завдяки тому що він дозволяє окремо враховувати похибки вимірювань і похибки випадкового процесу.

Однак для оцінки місцерозташування на пристроях Android загальна теорія зводиться до іншої форми. Провайдери розташування Android надають місцерозташування у вигляді широти і довготи разом з точністю, яка визначається як єдине число, виміряне в метрах. Реалізація рішення передбачає, що найкраща оцінка поточного місцезнаходження є останнім відомим місцем розташування, і якщо об'єкт перебуває у русі, то можливо використовувати приймачі Android пристрою для отримання більш точної оцінки $[9,10]$.

По-перше, фільтр Калмана є алгоритмом оптимальної рекурсивної обробки даних. Існує безліч способів визначення оптимальних засобів, що залежать від критеріїв, обраних для оцінки ефективності. Одним з аспектів оптимальності є те, що фільтр Калмана включає всю інформацію, яка може бути надана йому. Він обробляє всі дані доступні для виміру, незалежно від їх точності, для оцінки поточного значення змінних, що представляють інтерес, з використанням.

\section{Висновки.}

1. У статті проведено аналіз методів вимірювання обробки навігаційних даних 3 метою підвищення точності визначення місцезнаходження рухомого об'єкта та достовірності отриманої інформації .

2. Проаналізовано основні джерела помилок, що вносять похибки в обчислення точності навігаційних повідомлень у системі GPS.

3 .Показано та визначено основні джерела похибок, які впливають на точність навігаційних обчислень в GPS системах.

4. Розглянуто метод фільтрації Калмана, як один із сучасних методів фільтрації геолокаційних даних.

5. Фільтрацію доцільно проводити спочатку на джерелі даних, а потім на споживачі інформації. Попередня фільтрація дозволяє позбутися від надлишкових і помилкових даних, тим самим знизивши навантаження на канал передачі даних. Остаточну фільтрацію необхідно виконувати на високопродуктивних системах з метою отримання максимально ефективної фільтрації. 
1. Как работает GPS, принципы работы GPS [Електронний ресурс] - Режим доступу: www.tracker.co.ua/gps_work.html (дата звернення: 20.05.2018)- Назва з екрану.

2. Welch G., Bishop G. An Introduction to the Kalman Filter: Tech. Rep. TR- 95-041. [Електронний ресурс] - Режим доступу https://www.cs.unc.edu/ welch/media/pdf/kalman_intro.pdf. (дата звернення: 20.05.2018)Назва з екрану.

3. Савчук С.Г. Експериментальні дослідження точності визначення координат методом RTK $з$ використанням GPRS INTERNET з'єднання / С.Г. Савчук, А.В. Задемленюк, A.Я. Піскоровський // Сучасні досягнення геодезичної науки та виробництва. Вип. I (17). 2009.Львів - 2009., - С.58-69.

4. Задемленюк А.В. Дослідження впливу похибок на супутникові вимірювання в RTK режимі / А.В. Задемленюк // Геодезія, картографія і аерофотознімання / Вип. 73. 2010. Львів - 2010. - С. 25-33.

5. Задемленюк А.В. Результати експериментальних досліджень точності визначення координат та практичне застосування RTK-технології з використанням GPRS Internet з'єднання / А.В. Задемленюк // Геодезія, архітектура та будівництво. - Вип. 2. - Львів, 2009. - C.130-133

6. Задемленюк А.В. Дослідження похибок супутникових вимірювань в RTK режимі / А.В. Задемленюк // Нові технології в геодезії та землевпорядкуванні. Вип. 5. - Ужгород, 2010. - C.90-93.

7. Гоффман-Велленгоф Б., Ліхтенеггер Г., Коллінз Д. Глобальна система визначення місцезнаходження (GPS): Теорія і практика /Пер. $з$ англ. - К.: Наукова думка, 1996. 392 c.

8. Вихров Н.М., Каторин Ю.Ф. О безопасности инфраструктуры водного транспорта // Морской вестник,2014 № 4 (52) .С.99-102.

9. Вайгандт Н.Ю.,Нырков А.П. Повышение точности навигационных систем водного транспорта при помощи технологии референцных станций // IT: ВЧЕРА,СЕГОДНЯ,ЗАВТРА материалы науч.-техн.конф 2013,СПб.: ГУМРФ имени адмирала С.О.Макарова,2013.С.64-69.

10. Н.Т.Дехтярук,В.М.Черевик,О.В.Охріменко . Аналіз похибок позиціонування наземних обєктів засобами супутникової навігації. Зв'язок Наукове видання. Державний університет телекомунікацій.-Київ,2019 №5 стр. 3-7

\section{REFERENCES}

1. How GPS works, GPS principles [Online resource] - Access mode: www.tracker.co.ua/gps_work.html (accessed: 05/20/2018) - Screen name.

2. Welch G., Bishop G. An Introduction to the Kalman Filter: Tech. Rep. TR- 95-041. [Online resource] - Access mode https://www.cs.unc.edu/ welch/media/pdf/kalman_intro.pdf. (accessed: 05/20/2018) - Screen title.

3. Savchuk SG Experimental studies of RTK accuracy using GPRS INTERNET connection / SG Savchuk, A.V. Zademlenyuk, A.Ya. Piskorovsky // Modern achievements of geodetic science and production. No. And (17). 2009. Lviv - 2009., P.58-69.

4. Zademlenyuk AV Investigation of the effect of errors on satellite measurements in RTK mode / A.V. Zademlenyuk // Geodesy, Cartography and Aerial Photography / Iss. 73. 2010. Lviv 2010. - P. 25-33.

5. Zademlenyuk AV Results of experimental studies of coordinate accuracy and practical application of RTK technology using GPRS Internet connection / AV Zademlenyuk // Geodesy, architecture and construction. - No. 2. - Lviv, 2009. - C.130-133 
6. Zademlenyuk AV Research of errors of satellite measurements in RTK mode / A.V. Zademlenyuk // New technologies in geodesy and land management. No. 5. - Uzhgorod, 2010. - C.90-93.

7. Goffman-Wellenhof B., Lichtenegger G., Collins D. Global Positioning System (GPS): Theory and Practice / Trans. from English. - K .: Scientific Thought, 1996. - 392 p.

8. Vihrov NM, Katorin Yu.F. On the safety of water transport infrastructure // Maritime Bulletin, 2014 № 4 (52) .C.99-102.

9. Vaygandt N.Yu., Nyrkov A.P. Improving the accuracy of navigation systems of water transport using the technology of reference stations // IT: Yesterday, TODAY, TOMORROW materials scientifically-technical conf. O. Makarov, 2013.C.64-69.

10. NTDekhtyaruk, VM Cherevik, OV Okhrimenko Analysis of errors of positioning of terrestrial objects by means of satellite navigation. Communication Scientific Edition. State University of Telecommunications.-Kiev, 2019 №5 pp. 3-7

\section{Okhrimenko O.V.}

\section{METHODS TO IMPROVE THE ACCURACY OF POSITIONING OBJECTS BY MEANS OF SATELLITE NAVIGATION}

The analysis of the processing navigation data in the tracking systems of moving objects, namely the method which increases the accuracy of measurement of coordinates, the algorithm of the Kalman filter. To a large extent this applies to various moving objects-the movement of air ,sea, river, automobile and railway transport, as well as the use of modern satellite navigation systems in related fields, such as geodesy and cartography, land management, monitoring of the earth's surface. The algorithm of the Kalman filtering sequential recursive algorithm using the adopted model of the dynamic system to estimate, which may be significantly adjusted as a result of the analysis of each new sample measurements in time order. It is a recurring method that you can carry on the algorithm to the method of substitution. The algorithm of Kalman filter is used in the management of many complex dynamic systems, as this mathematical apparatus, which allows to smooth the data on the fly, not accumulating them for analysis. When controlling a dynamic system, it is first necessary to completely know the phase state at each point in time, but to measure all the variables that you want to manage is not always possible and in these cases the Kalman filter is a tool that allows you to restore missing information with the available inexact (noisy measurements.

Keywords: satellite navigation systems, methods of processing the navigation data, the accuracy of measuring coordinates, the method of Kalman. 